\section{La arabidad en la narrativa sudamericana de la segunda mitad del siglo XX y la literatura del Mahyar}

Arabness in the South American narrative of the second half of the 2oth Century and the literature of the Mahyar

Leyla Bartet

\section{RESUMEN}

Desde finales del siglo XIX llega a las costas americanas una importante inmigración de origen levantino. Este movimiento migratorio se prolongó a lo largo del siglo XX dejando una huella profunda en la vida cotidiana y en la historia de nuestros pueblos. La experiencia del encuentro cultural es recogida ampliamente por el discurso literario que es espejo y proyección de nuestra identidad conflictiva, diversa y múltiple. La mayoría de los inmigrantes eran campesinos o pequeños comerciantes empobrecidos. Pero también llegaron a América intelectuales sirios, libaneses y palestinos que crearon círculos literarios e importantes escuelas que revolucionaron la producción literaria en lengua árabe: la llamada literatura del Mahyar. El estudio abordará el tema desde; el discurso literario del enunciante ajeno al mundo árabe, el discurso literario del enunciante árabe (o de origen árabe) y la literatura del Mahyar: el renacimiento literario árabe desde América.

Palabras clave: Literatura; Arabidad; Inmigración; Antropología cultural; Identidad

\section{ABSTRACT}

From the end of the 19th century, an important Levantine immigration movement reached the American coasts. This migration continued throughout the 2oth century, deeply impacting the daily life and history of our continent. The experience of this cultural encounter is widely reflected in the literary discourse that functions as a mirror, projecting our conflicting, diverse and multiple identities. Most of the immigrants were impoverished peasants or small merchants. However, Syrian, Lebanese and Palestinian intellectuals also came to America and created literary circles and important schools that revolutionized literary production in the Arabic language: It is the so-called Mahyar literature. The study will approach the subject from; the literary discourse of the non-Arab enunciator, the literary discourse of the Arab enunciator (or of Arab origin) and the Mahyar literature: the Arab literary renaissance from America.

Keywords: Arabity; Inmigration; Cultural Anthropology; Identity

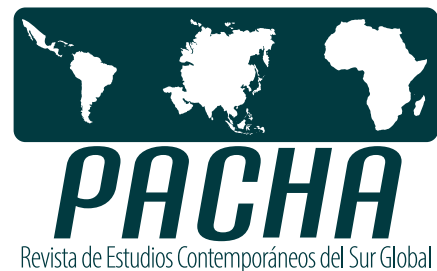

Revista de Estudios Contemporáneos del Sur Global

INFORMACIÓN:

https://doi.org/10.46652/pacha.v2i6.70 ISSN 2697-3677

Vol. 2, No. 6, 2021. e21070

Quito, Ecuador

Enviado: agosto 12, 2021

Aceptado: octubre 15, 2021

Publicado: octubre 28, 2021

Sección Dossier | Peer Reviewed

Publicación continua

\section{(1) $\Theta \Theta$ open 2 access}

\section{AUTORA:}

(D) Leyla Bartet

Organización de las Naciones Unidas para la Educación, la Ciencia y la Cultura - Francia

leylabartet@gmail.com

\section{CONFLICTO DE INTERESES}

La autora declara que no existe conflicto de interés posible.

FINANCIAMIENTO

No existió asistencia financiera de partes externas al presente artículo. NOTA

Es parte del proyecto presentado en el Foro ASPA (América del Sur / Paises Árabes) en la Reunión de Ministros de Cultura realizada en Santa Cruz, Bolivia, en el año 2007.

ENTIDAD EDITORA 


\section{Introducción}

En Raza, Nación y Clase: las identidades ambiguas, un libro de ensayos publicado inicialmente en 1987 y reeditado diez años después, uno de los autores (Immanoel Wallerstein) sostenía que la identidad es un concepto en movimiento y en perpetua construcción cuyos límites cambian en cada caso particular. La post modernidad nos demuestra hasta qué punto, por un concepto tan volátil, los gobiernos y los movimientos políticos que utilizan un "discurso nacional" están dispuestos a llevarnos a matar o morir.

Tal pareciera que América Latina, ese continente caleidoscopio como lo llamara el antropólogo español Manuel Gutiérrez Estévez, se habría visto preservado de grandes guerras vinculadas a la cuestión identitaria. No es tan cierto: más allá de los enfrentamientos vinculados a conflictos por una delimitación fronteriza, siguen existiendo formas de enfrentamiento vinculadas a diferencias culturales, étnicas y sociales dentro de cada uno de los Estados. Con razón precisa Gutiérrez Estévez que América Latina se presenta como un texto infestado de rupturas y, si se examina de cerca el continente, pueden verse las estrías que separan a los grupos humanos que lo conforman y que parecen pertenecer a universos temporales diferentes a pesar de ser todos contemporáneos.

\section{Condiciones de producción del discurso literario sobre la arabidad}

La cultura hispanoamericana nació intercultural en el proceso de cruce, asimilación, superposición y síntesis de elementos indígenas y europeos. Los textos de los cronistas del descubrimiento y de la progresiva ocupación del territorio muestran el asombro por la existencia del "otro" y de "lo otro". Pero es importante señalar que los europeos (españoles y portugueses esencialmente) traían también una idea de la alteridad profundamente marcada por su reciente experiencia de la reconquista de Granada y por sus relaciones anteriores con la civilización de Al-Andalus. En este sentido, no resulta extraño que, por ejemplo, las crónicas de Pedro Cieza de León (El señorío de los Incas) designaran los templos indígenas como "mezquitas". También Bernal Díaz del Castillo (La historia verdadera de la conquista de Nueva España) sostiene que el expedicionario Francisco Hernández de Córdoba califica la primera gran ciudad azteca que encuentra en su camino hacia la capital azteca de "Gran Cairo". Otro cronista español, González de Nájera, quien aprecia la valentía de los guerreros araucanos, en Chile, dice de ellos que "combaten como moros". El otro exterior, es decir el indio, es designado con una expresión utilizada en la península ibérica a comienzos del siglo XVI para referirse al otro interior, aquel que existe en el espacio que ocupa el enunciante. En el caso de los españoles se trataba del árabe, del infiel, de aquella persona distinta y presente. Así, árabes e indígenas son a sus ojos sino iguales, al menos equiparables.

Pero lo que nos llega de España está también profundamente marcado por el largo contacto entre árabes y españoles. En la línea de Américo Castro puede decirse que la herencia semítica es singularmente importante en la configuración de la identidad ibérica.

Esta interculturalidad espontánea se fue reduciendo, se fue haciendo cada vez más conflictiva. La relación difícil con el "otro-distinto de sí" (Calderón et al. 1996) se remonta al período de descubrimiento-conquista y evangelización. Pero no acaba allí, sino que sobrevive y se transfigura innumerables veces a lo largo de nuestra historia. Uno de los factores que determina un cambio importante en la percepción de la alteridad en el criollo latinoamericano del siglo XVII será, sin duda, su relación con los esclavos africanos que llegan a trabajar en las plantaciones y a reemplazar la mano de obra indígena que - ya lo había defendido Fray Bartolomé de las Casas en la controversia de Valladolid- los indios sí tienen alma. Luego, ya entrado el siglo XIX, los gobiernos criollos habrán de promover las oleadas de inmigrantes de diverso origen que llegan al continente "a hacer la 
América" cuando, tras las Independencias, los jóvenes Estados del continente toman conciencia de la importancia de ocupar el territorio y de poblar sus espacios.

El siglo XIX será aquel de las leyes que favorecen o limitan, según los períodos históricos y el tipo de migración que se propugne, la llegada de extranjeros deseosos de trabajar y prosperar en estas tierras

En este contexto, a partir de la segunda mitad del siglo antepasado, arriban a América Latina numerosos europeos del sur y del este y árabes del Levante Se calcula que entre 1860 y 1890 un número aproximado de 600 mil árabes abandonaron el Medio Oriente con América como destino. Este flujo se intensificó aún más entre 1900 y 1914, fecha en la que el inicio de la Primera Guerra Mundial pondrá fin al ya decadente Imperio Otomano, al cual pertenecían los territorios de Líbano, Siria y Palestina.

Así, el criollo latinoamericano agregará a su idea de alteridad aquella de los extranjeros y, en el caso que nos ocupa, de los árabes. La acogida que le reservan los países latinoamericanos a sirios, libaneses y palestinos varía mucho de un país a otro. Brasil promulga leyes que favorecen esta inmigración porque la vastedad de su territorio así lo requería. Chile y Argentina no siempre la ven con buenos ojos ya que asocian el árabe al asiático y porque optan abiertamente por una inmigración blanca. Colombia, Perú, Bolivia, Ecuador, Colombia y Venezuela adoptan una política de "Laisser faire, laisser passer”, con alguno que otro sobresalto marcado por el racismo y la intolerancia.

Esta importante inmigración árabe, que habrá de prolongarse a lo largo del siglo XX, deja una huella muy importante en la vida cotidiana y en la historia de nuestros pueblos. La experiencia de encuentro cultural es recogida ampliamente por el discurso literario. Y es lógico que así fuera porque, a la interculturalidad de cada país de acogida, se agregan los nuevos elementos que aportan los recién llegados. El discurso literario es, en este sentido, espejo y proyección de nuestra identidad conflictiva, diversa y múltiple. Así, numerosas obras se refieren a la presencia árabe en América desde finales del siglo XIX. En el caso del Perú se ha citado más de una vez a autores como Ricardo Palma o Juan de Arona (en particular, Las Memorias de un viajero peruano. Apuntes y recuerdos de Europa y Oriente 1859 -1863) Hasta antes de la fecha que nos ocupa otros autores sudamericanos abordaron en su escritura como Jorge Luis Borges y Roberto Artl, pero distan de ser los únicos.

Por razones de espacio un tema tan ambicioso y vasto como el propuesto no puede ser abordado en este trabajo más que de modo sucinto. Se trata de un esbozo de investigación inspirado en un proyecto que presenté en el marco de América del Sur-Países árabes (ASPA) un foro imaginado por el presidente Luiz (Lula) da Silva en el año 2003. ASPA supuso reuniones de ministros árabes y sudamericanos de diversas ramas a lo largo de los años y hasta 2012. En el año 2007, este proyecto fue presentado en la reunión de ministros de Cultura en la ciudad boliviana de Santa Cruz y aprobado por quienes asistieron al evento. Pero no se llevó a cabo por falta de coordinación entre los ministerios de los países que se mencionan en el proyecto. Entregué el texto también a la Casa Árabe de Madrid en el 2009.

Como afirmo más arriba, la amplitud del tema impide que se aborde de manera exhaustiva la obra de los numerosos autores del continente que, de un modo u otro, establecen un puente de miradas cruzadas sobre la arabidad. El objetivo, más modesto, es simplemente suscitar el interés y abrir brechas hacia un estudio profundo y sistemático.

A partir de 1950 el discurso narrativo sobre la arabidad puede abordarse desde dos perspectivas distintas. 


\section{Discurso literario del enunciante ajeno al Mundo Árabe}

Se trata aquí de los textos que señalan la presencia de un sujeto distinto o de un universo diferente al propio. Por ejemplo, Gabriel García Márquez en Cien años de soledad, se refiere a los primeros habitantes de Macondo como gitanos árabes que llegan con sus argollas y babuchas, dispuestos a vender diversas baratijas. Cuando el pueblo de Macondo empieza a organizarse, una de las primeras calles se bautiza como "Calle de los Turcos". Otra de sus novelas, Crónica de una muerte anunciada, tiene como personaje central (la víctima) al joven Santiago Nasar, hijo mestizo de árabe y colombiana. Este universo tiene como asidero el hecho histórico que la inmigración árabe a Colombia ingresa por la costa del Caribe para adentrase progresivamente hacia el valle de rio Magdalena. Así, Barranquilla, Cartagena y otras ciudades costeras vieron establecerse un número importante de familias árabes que siguieron llegando hasta la Segunda Guerra Mundial. Como dato curioso, la esposa de García Márquez, Doña Mercedes Barcha, es de ascendencia árabe (egipcia) y nacida en la ciudad de Sucre, donde se ambienta Crónica de una muerte anunciada. En esta breve novela el autor colombiano aborda con fineza los elementos posibles de la construcción de una identidad mestiza de árabe e hispano. El sentimiento del honor y la venganza destacan entre sus rasgos. Pero también una inexplicable tristeza conformista que responde a uno de los tópicos sobre la arabidad. Como lo señala el estudioso cubano Rigoberto Menéndez Paredes:

\footnotetext{
En la tragedia actúan las diferencias culturales y raciales así como desniveles de clase social, el lector no percibe una novela de emigración sino un drama policial con el trasfondo de un escenario latinoamericano, pero encuentra huellas diversas de lo que fue la inmigración árabe en territorio colombiano (2011).
}

También el escritor brasileño Jorge Amado hace figurar a personajes de origen árabe en sus novelas. Es el caso, por ejemplo, de Gabriela, clavo y canela (Nacif, el próspero comerciante libanés enamorado de la bella Gabriela), de Tocaia Grande (Fadul Abdala, protagonista de la gesta del cacao) y de El descubrimiento de América por los Turcos.

Otro gran escritor brasileño, Joao Guimaraes Rosa, describe al personaje de Seo Assis Wababa, mercader oriental establecido en los confines del Gran Sertón. En su gran novela Grande Sertao. Veredas (1956), Guimaraes presenta a este árabe, feliz en su papel de jefe de familia numerosa y padre de la bella Rosa'uarda (uarda significa rosa en árabe). Wababa habla un dialecto árabe y tiene relaciones conviviales con sus vecinos, desencadenando la xenofilia de Riobaldo, personaje principal de la novela.

Por otra parte, el gran escritor argentino Jorge Luis Borges dibuja, en su clásico de la narrativa hispanoamericana del siglo XX, Ficciones, personajes que se mueven en un Medio Oriente cargado de símbolos metafísicos. Con frecuencia son lectores eruditos de las Mil y Una Noches. En 1936, en Historia Universal de la Infamia, Borges presenta personajes directamente inspirados de los cuentos de Shéherezade. En el prólogo, el autor precisa que, en realidad, ha transformado las historias ajenas con un interés puramente literario. Menciona el caso de dos cuentos que integran esta antología: La cámara de las estatuas, inspirada en la noche 272 y La historia de los dos que soñaron que se basa en la noche 351 de Las mil y una noches. En El Aleph también hay más de un cuento de visos orientales (I.e. El jardín de los senderos que se bifurcan). Pero es, en conjunto, un ambiente, un modo de entender la realidad y la eternidad, el gusto por la narración en abismo (el cuento dentro del cuento), características todas muy frecuentes en la literatura árabe, lo que palpita en la narrativa de Borges. 
En su libro de ensayos titulado Siete noches, el autor aborda las Mil y una noches desde una perspectiva que habría resultado interesante a Edward Saíd. Este, en su clásico Orientalismos, critica la construcción ideológica de un Oriente, no sólo cargado de prejuicios, sino construido como espejo invertido. Se acepta del otro aquello que nos asemeja a él. El resto es materia de cliché. En mi opinión, la lectura de Borges ocurre desde una perspectiva clásica marcada por griegos y latinos y muy en la línea de lo que se conoció como los orientalistas británicos. La "deconstrucción" del discurso de los no-árabes sobre lo árabe en literatura merecería ser abordada entro de un marco teórico más riguroso que lo realizado hasta hoy.

Más cerca de nosotros y en un contexto definitivamente contemporáneo de cosmopolitismo parisino, el escritor colombiano Santiago Gamboa presenta, en su más reciente novela El síndrome de Ulises, a autores marroquíes e iraquíes enfrentando las dificultades de vivir en el universo difícil y con frecuencia hostil de la inmigración en Francia. También otro joven colombiano Antonio Ungar, autor de Las orejas del lobo, quien vivió algún tiempo en Jaffa antes de retornar a su país casado con la escritora palestina Zahiye Kundos, es digno de mención.

También el escritor peruano José de Piérola imagina un oriente en el que no vive (radica en Estados Unidos) en su novela Shatranj, el juego de los reyes, una suerte de parábola del ajedrez que ocurre en un Irán ya islamizado. Precisando que Irán sin ser un país árabe, forma parte de la Umma, la comunidad de creyentes que une al mundo musulmán.

Un ejemplo a citar es el de Eva Luna (1987), Best Seller de la chilena Isabel Allende. Zulema, la mujer (¿libanesa? ¿siria?) y su sobrino político Kamal viven una pasión incontrolada a espaldas del bueno de su marido, Riad Halabi. La obra se hace eco de todos los tópicos del exotismo y la sensualidad orientales. En los capítulos 6 y 8 de la novela se describe a un Halabi que viene del desierto y se muere de nostalgia de camellos y nomadismo, cuando los levantinos que llegan a América no eran beduinos, sino campesinos y grandes agricultores desde hacía 1300 años, nuevos pobres que la miseria y la guerra habían empujado a la emigración. La obra de Isabel Allende se construye sobre los clichés circulantes en América Latina.

\section{Discurso literario del enunciante árabe o de origen árabe}

Es la producción de lo que se llama la Faliya, la diáspora, la comunidad que se instala en América del Sur. La fuente de inspiración es la experiencia vivida directamente por el inmigrante o es hija de la memoria familiar.

Dentro de esta forma discursiva es preciso diferenciar los textos de aquellos que llegan a América como inmigrantes y, en un género que podría calificarse de literatura etnocultural, describen su experiencia en el país de acogida. Sus referentes culturales son distintos, pero la tendencia a la percepción selectiva de las diferencias contribuye a la producción del fenómeno de atribución identitaria. Ejemplos de esta forma literaria que describe la experiencia de la alteridad "desde dentro" son las obras del sirio Benedicto Chuaqui, Memorias de un emigrante en Chile y también aquellas del palestino Roberto Sarah (Los turcos) de José Auil, (La aldea blanca), de Walter Garib (El viajero de la alfombra mágica) o de Edith Chain (Nahima y Fahdua).

El caso de Benedicto Chuaqui Ketlun (1895-1970) es un buen ejemplo del ejercicio de inserción y de comprensión de aproximaciones y diferencias con la sociedad de acogida. Chuaqui llega a Chile en 1908, a la edad de 13 años. Se esfuerza por aprender el español académico y se convierte en un escritor bilingüe. En 1942 publica Dos razas a través de sus refranes, verdadero tratado de paremiología comparada. Más tarde publica numerosos ensayos y artículos sobre la obra y el pensamiento de Khalil Gibran Khalil. Fundador del Instituto Chileno-Árabe de Cultura construyó un verdadero puente de intercambio literario entre Chile y el Mundo Árabe. 
Los inmigrantes levantinos debieron hacer frente a circunstancias a veces muy difíciles. En Argentina y Chile eran objeto de insulto y de desprecio y antecediendo a situaciones que hoy vuelven a verse, hubo navíos cargados de inmigrantes 'árabes que fueron detenidos por las autoridades portuarias de Buenos Aires impidiéndose el descenso de sus precarios pasajeros. En Chile se instalaron en ciudades o puertos (en particular en Valparaíso) donde vivían en tugurios y conventillos. Más tarde adquirieron prestigio y fortuna. Esta historia inicial es narrada también por algunos autores.

"Turco muerto de hambre" fue el primer insulto que Hannah Nabal (quien luego castellaniza su nombre a Juan Nabal) escuchó al desembarcar en Buenos Aires. En la novela de Roberto Sarah. Sarah narra las vicisitudes de un inmigrante palestino en Argentina y luego en Chile donde finalmente se instala.

Dentro de esta categoría es posible citar igualmente al novelista brasileño de origen libanés, Emile Farhat quien en su obra Dinhero da estrada: uma saga de inmigrantes hace la siguiente descripción del espacio que ocupaba América en el imaginario colectivo levantino.

América atrae porque América no acaba. No tiene fin, nunca se detiene. Nada tiene límites ni vecinos. La vida se vive en doble porque no hay horas vacías (...)Aunque uno no se mueva, se verá arrastrado por la corriente. O se ahoga...o sigue adelante con el mismo espejismo: el espejismo que el dinero sigue allí tirado en el camino (1987).

Frente a estos textos, que describen una experiencia vivida, se encuentran aquellos que se aproximan más a las formas canónicas de la literatura occidental. Es decir, a una construcción imaginaria basada en el recuerdo, siempre subjetivo, de una experiencia anterior pero vinculada a la existencia del autor. Se trata aquí de la abundante literatura producida por los descendientes de los inmigrantes árabes, como Miguel Littin (1942), escritor y cineasta chileno, autor de El viajero de las cuatro estaciones (1990) y de El bandido de ojos transparentes (1999) o el también chileno Walter Garib (1933) que ha publicado, entre otra novela El viajero de la alfombra mágica (1991). En esta obra Garib evoca la historia de una familia libanesa que alcanza éxito económico y reconocimiento social en Chile, pero afirma que sus orígenes son italianos (el apellido Magdalani, puede pasar por italiano en Chile) para evitar que se critique sus orígenes de "turco muerto de hambre". Tras una fiesta en su casa sufre ofensas por parte de la aristocracia local por ser un "nuevo rico" hijo de la inmigración. La novela intenta mostrar, por una parte, el esfuerzo extremo del inmigrante por insertarse en la sociedad de acogida imitando los patrones de éxito locales y, por otra, las limitaciones de esta aculturación.

Cabe citar igualmente a los brasileños Milton Hatoun y Raduan Nassar. Hatoum cuenta sus orígenes libaneses, cristianos y musulmanes en un artículo que fue publicado en el 2005 en la revista del Institut du Monde Arabe (IMA), Quantara, que aquí citamos.

A inicios del siglo XX, durante el apogeo del ciclo del caucho, mi abuelo paterno deja Beyrut para instalarse en Acre donde trabaja como vendedor ambulante a lo largo del río, entre las ciudades de Rio Branco y Xapuri. Fue uno de los primeros inmigrantes libaneses de mi familia. Ocho años más tarde volvió a Beirut cargado de imágenes y de palabras de la Amazonía que transmitió a sus familiares y a sus hijos.

Dicen que contaba historias inverosímiles de naufragios, duelos, inundaciones, epidemias, cacerías en plena selva.

Mi padre creció arrullado por estas historias y decidió viajar e instalarse en Acre. Se fue acompañado de un primo poco antes de la Segunda Guerra Mundial. A su 
paso por Manaus, conoció a mi madre nacida allí, pero hija de libaneses del norte y cristiana. El matrimonio entre una marónita y un musulmán (mi padre lo era) podía ser mal visto en Libano pero no en Brasil.

Hatoum (1952) es un autor cuya obra ha sido traducida y llevada al cine. Dos de ellas Relato de un cierto Oriente (traducida del portugués al español en 2001) y Dos hermanos (2003). Ambas se desarrollan en un Manaos en plena decadencia y en un medio que es el de la inmigración libanesa. Este reconocido autor se siente heredero de una cultura múltiple en la que lo árabe está presente, pero en un contexto marcadamente brasileño.

Es difícil definir lo que somos, pero un brasileño descendiente de inmigrantes, sean cuales fueren sus orígenes, no siente el extrañamiento y la distancia cultural que un magrebí en Francia o que un pakistaní en Gran Bretaña. Nosotros no nos consideramos como afro-brasileños, ítalo-brasileño, germano-brasileños o árabe-brasileños, no compartimentamos la realidad, no clasificacmos a la gente en función de su etnia. La dilución de los orígenes está en el origen de la formación de la sociedad brasileña (2005, pp. 39-42)

Hatoum explica la pérdida de la lengua materna porque era considerada la lengua del pasado. El portugués brasileño era la modernidad.

Los viejos libaneses amigos de mi padre contaban historias de desplazamientos, de aventuras, de desplazamientos por el Amazonas, comerciando a lo largo de sus puertos. Se desprendía de estas narraciones su deseo de triunfar en la nueva patria. El árabe era hablado por mi padre y mis abuelos maternos. Pero mi madre que ya había nacido en Brasil, no pronunciaba una palabra en ese idioma. Para mí, el árabe fue una suerte de melodía hecha de sonidos familiares pero lejanos. Poco a poco se convirtió en un conjunto de sonidos que la memoria me recordaba conforme los más viejos iban desapareciendo.

La familia de mi madre era musulmana, la de mi padre maronita. La Biblia y el Corán eran los dos libros sagrados de mi casa y ninguna religión me fue impuesta.

Este cruce de culturas y de orígenes fue crucial para mi infancia y adolescencia. Comprendí que emigrar significa perder una parte de sus orígenes y asimilar la nueva cultura (2005, pp. 39-42).

Por otra parte, Radouan Nassar (1935) autor de tres libros destacados, renueva el paisaje literario brasileño de los años 70 del siglo pasado. El más innovador es La casa de la memoria (1975). Su obra a pesar de ser reducida y poco traducida es considerada como el inicio del vanguardismo reciente brasileño, esencialmente urbano y con un tiempo narrativo mítico. Aparece como trasfondo la memoria libanesa de sus orígenes, con referencias a textos primordiales como la Biblia (Nassar es de origen libanés maronita) y La mil y una noches.

En Argentina, Jorge Assis (1946) (conocido como "el turco Assis) y el recientemente fallecido Juan José Saer (1937). Jorge Assis es hijo de sirios, periodista y escritor, ha publicado más de 20 libros. Cabe destacar Don Abdel Salim, el burlador de Doménico (1972) y Flores robadas en los jardines de Quilmes (1980) verdadero best-seller en Argentina. Muy vinculado al menemismo, fue profesor de 
historia del cine. Vivió en Paris desde 1968 escribiendo y trabajando como profesor universitario. Se le conocía también con el sobrenombre de Juanjo, el turco. Es autor de novelas, poesía y ensayos y ganador del Premio Nadal de novela con su obra La Ocasión (1987). Falleció en 2005.

También puede mencionarse al escritor Jorge Enrique Adoum, ecuatoriano descendiente de libaneses. A pesar de sus éxitos literarios estos dos últimos autores evocan poco o nada sus orígenes levantinos. En cambio, el tema está muy presente en el caso de Assis.

Otro autor que merece ser mencionado es el escritor colombiano Luis Fayad. En su novela La caída de los puntos cardinales narra las aventuras de su padre libanés quien llega a las costas colombianas gracias a una escala del barco que debía llevarlo a Chile donde tenía parientes establecidos desde hacía un tiempo, en la clásica inmigración del llamado. Durante la travesía pierde en juegos de azar buena parte del dinero que llevaba para establecerse en Valparaíso y decide quedarse en la costa colombiana para trabajar un tiempo, recuperar el dinero y continuar viaje. Pero no puede resistirse al encanto del lugar y de una mujer en particular. Así que se queda donde ha llegado.

Entre los más jóvenes puede citarse los nombres de Lina Maruane y Tatiana Cumsille (Chile), Rodrigo Hasbún (Bolivia), Eduardo Halfon y Carolina Sanin (Colombia).

\section{La literatura en lengua árabe del siglo XX producida en América del Sur}

En el marco de este trabajo nos ha parecido interesante comentar igualmente lo que se produjo en América utilizando el árabe como forma de expresión. Precisamente por el escaso conocimiento de esta lengua en nuestro continente se trata de una literatura poco conocida y estudiada y consumida casi exclusivamente en medios académicos. Sin embargo, tuvo importantes repercusiones en los países de origen de estos escritores y poetas árabes sudamericanos y en general en toda la producción del Mundo Árabe. Se trata de una corriente conocida como la Literatura del Mahyar, del exilio o de la diáspora. El ensayista y poeta libanés George Saidah fue uno de los primeros en estudiar el fenómeno de Adab al-Mahyar y contabiliza en sus inicios a unos 85 intelectuales sirios, libaneses y palestinos. A diferencia del capítulo anterior referido exclusivamente a la narrativa de la segunda mitad del siglo XX, en este capítulo se ha incluido la poesía árabe escrita en Sudamérica a lo largo de aquel siglo.

La masiva llegada de inmigrantes levantinos desde finales del s. XIX y en la primera mitad del S.XX supuso la apertura de centros escolares árabes, clubes y asociaciones diversas, iglesias de ritos cristianos orientales o católicos maronitas y mezquitas musulmanas, diarios y revistas en árabe. En efecto, en aquellos lugares donde la masa migratoria fue importante (Brasil, Argentina, Chile), junto con aquellos que huían de la pobreza, de las crisis económicas y de la guerra, llegaron también destacados intelectuales panarabistas que rechazaban las restricciones impuestas desde todo punto de vista por el Imperio Otomano y más tarde por las potencias occidentales en el período de los mandatos francés y británico.

Ante el estancamiento de la literatura árabe hacia finales del siglo XIX escritores de la talla de Yibran Jalil Yibran promueven, desde su exilio neoyorkino, un movimiento de renovación de las letras árabes.

Los intelectuales más activos de la diáspora brasileña deciden iniciar a su vez una innovación formal y temática a partir de su experiencia en tierras americanas, inspirándose en lo realizado en Nueva York. El primer poeta que asume el camino del cambio en Brasil es Fawsi al-Maalouf (1999-1930). En 1921 se instala en Sao Paulo donde se dedica al comercio y a la poesía. Es reconocido como uno de los grandes poetas de su generación por su libro Sobre la alfombra de viento. 
Poema en catorce cantos publicado a título póstumo y traducido a diversos idiomas. Cada canto está compuesto de 16 versos de rima única, fuera de los dos primeros que, como preludio, poseen una rima diferente. La obra se caracteriza por su tono radicalmente pesimista, como un espíritu prisionero en la tierra y predestinado a una evasión que se encuentra en la muerte. En Nostagia del emigrante, otro largo poema, el autor expresa su nostalgia por la tierra perdida, un tema recurrente en la literatura del Mahyar. Su programa, como hemos indicado, se inspira del movimiento precursor de Jalil Yibran, la Liga del Cálamo (Al Râbbita al-Qualamiyya) que marcará un punto de inflexión en el desarrollo de la literatura árabe moderna introduciendo, a nivel formal, el uso del verso libre y de la prosa poética. Los contenidos también se alteran y la nostalgia y la añoranza de la tierra natal aparecen como temas recurrentes. Por su parte, al- Usba al-andalusiyya propone una creación libre de las reglas de versificación y de la estética vigente hasta entonces. El verso libre parece más apropiado para desempeñar la función de mediador cultural entre la producción del Oriente árabe y aquella de la diáspora.

Entre sus seguidores se encuentran los poetas Rachid Alkhouri, Chafik Maalouf, Chrokrallah Aljure, Elias Farhat e intelectuales como Aql Aljuri, Tawfiq Qurban, Tawfiq Daroun, Abdouktour Bicharah y el erudito Moussa Kourayyim muy implicado en la teorización de la métrica.

A partir de 1935 se editará una revista literaria, al-Usbah, que logra sacar a luz 35 números, ofreciendo la obra literaria de la emigración árabe. Se trata de una producción de calidad desigual, pero expresa la identidad de esta corriente. Aquí publica Rachid Alkhouri, conocido como "el poeta rural" por oposición a su hermano que permaneció en el Líbano y a quien se conocía con el sobrenombre de "poeta urbano", escribe desde las descripciones y metáforas tradicionales, pero desde el otro lado del océano y canta, a la vez, a Granada, la andalusí y a Santos, la brasileña. Alkhouri se había establecido en este puerto de la costa sur de Brasil.

La obra de la mayoría de los autores del Mahyar constituye una suerte de exorcismo que se desprende de un doble desgarramiento a la vez físico (la distancia de la tierra natal) y lingüístico.

Chafiq Maalouf, quien junto con su hermano Fawsi, es muy activos en el seno de Al Usba al-andalusiyya asume los principios del cambio formal, pero sin renunciar al patrimonio de metáforas y metonimias tradicionales de la poesía árabe. Paradójicamente fue el más innovador en términos de estilo. Su obra más conocida es Abqar, un poema épico inspirado en mitos preislámicos. A lo largo de doce cantos la visión del autor asume una dimensión ontológica dónde el poeta aparece como mediador entre lo sobrenatural y los problemas existenciales del hombre: el amor, el odio, el arte, la poesía, la vida y la muerte.

Más allá de la innovación literaria y la frescura que la poesía de la Liga Andalusí introdujo en la literatura árabe de su época, sus autores permanecieron al margen de los movimientos vanguardistas que por esos años sacudían Brasil, en particular la corriente modernista que renovó el panorama intelectual brasileño y que tuvo expresiones en todos los niveles del arte y la literatura.

\subsection{Argentina}

El efecto de estos círculos literarios (el de Nueva York y el de Brasil) se dejó sentir en otros países de la región, en particular en Argentina y Chile.

En 1949 se funda en Argentina Al- Rabbita al-adabiyya (la liga literaria). Sus primeros integrantes fueron Yuri Assaf, jefe de Redacción del periódico en lengua árabe Al-Salam, el escritor Yubran Massuh, Yussef Sarmi, propietario de la revista Al-Muwahid y otros periodistas, poetas y traductores. Pero este círculo fue de corta duración. Los escritores se reunieron durante dos años en casa del filósofo y poeta Yori Saideh y luego la asociación desapareció. 
Según el poeta palestino radicado en Argentina, Juan Yasser (1996) los escritores de la diáspora argentina volvieron a reencontrase años después, en 1957, en la Peña de literatura árabe que tuvo una vida algo más larga.

Este movimiento argentino no tuvo la repercusión transoceánica que conoció la liga brasileña. Merece ser destacado, sin embargo, el poeta Yuri Saydah quien vivió a caballo entre Damasco, Brasil, Venezuela y Buenos Aires. Como se ha mencionado anteriormente, fue fundador de la Liga argentina y de un destacado estudio titulado Nuestra literatura y nuestros escritores entre la inmigración americana, obra de referencia sobre el tema.

Cabe señalar que los autores vinculados a este movimiento continuaron escribiendo en árabe hasta bien entrada la segunda mitad del siglo XX. Así, el poeta sirio Zaki Konsol (1916-1994) continúa publicando su poesía en la década del 70. Tanto Zaki Konsol como su hermano, lliâs, manifestaron una notable influencia de los poetas de Al-Usba al-andalusiyya de Brasil. Iliâs Zaki fue, además novelista y ensayista. Destacó por su condición de bilingüismo, la misma que le permitió traducir la obra de Jalil Yibrán al español.

\subsection{Chile}

La inmigración levantina a Chile, a pesar de su importancia numérica, fue menor que a Brasil y Argentina (en este orden). Si bien aparecieron publicaciones y periódicos en lengua árabe, la aparición de ligas o peñas literarias fue de importancia menor y más tardía. Al respecto, cabe mencionar la obra de Matías Rafide Escritores chilenos de origen árabe (1989).

En 1955 se funda Ad-Nadwa al-arabiyya. La iniciativa, lanzada por la escritora Mari Yanni Atallah, reunió a un grupo de intelectuales de origen árabe decididos a visibilizar el legado en árabe de autores como Benedicto Chuaqui (1895-1970) quien, tras su llegada a Chile en 1908, aprendió el castellano y se convirtió en un escritor bilingüe.

Esta experiencia fue de poca duración, aunque contribuyó a dar a conocer la obra de este importante autor.

\section{Conclusión}

El fenómeno de las ligas literarias árabe americanas que siguen el camino inicialmente trazado por Jalil Yibran en Nueva York abre numerosas pistas de estudio. Más de un investigador ha trabajado sobre el tema, tanto en los Países Árabes como en América del norte y del sur, pero este dista mucho de estar agotado. Su interés y su particularidad radica en que es la única experiencia conocida de innovación literaria producida fuera del territorio lingüístico de origen y que renueva toda la literatura producida en ese espacio. Como un boomerang los autores levantinos vinculados a estos círculos literarios de la diáspora promovieron un "renacimiento" de la literatura árabe contemporánea.

\section{REFERENCIAS}

Amado, J. (1991). El descubrimiento de América por los turcos. Alianza editorial

Amado, J. (2001). Tocaia Grande. El Aleph

Amado, J. (2016). Gabriela, clavo y canela. Alianza Editorial

Arona, J. (1971). Memorias de un viajero peruano. Apuntes y recuerdos de Europa y Oriente 1859-1863. Ed. Biblioteca Nacional

Assis, J. (1972). Don Abdel Zalim. El burlador de Domenico. Ediciones Corregidor

Balibar, E., y Wallerstein, I. (1997). Race, nation et clase. Les identités ambiguës. La Decouverte 
Bartet, L. (2011). Memorias de cedro y olivo. La inmigración árabe de al Perú de 1885 a 1995. Fondo Editorial del Congreso del Perú.

Bartet, L. (2011). Las fronteras disueltas. Voces árabes en el Perú Ss. XIX y XX. Lima Fondo Editorial del Congreso del Perú.

Borges, J. L. (1981). Obras Completas. Alianza Editorial

Chahuan, E. (2005). Los palestinos en Chile, una dolorosa integración. Quantara. Magazine des cultures árabes et méditérranéenne, $\mathrm{n}^{0} 56$

Chuaqui, B. (1942). Memorias de un emigrante y Dos razas a través de sus refranes. Ed. Orbe

Farhat, E. (1987). Dinhero da estrada. Uma saga de inmigrantes. Ed. T.A. Queiroz

Fayad, L. (2001). La caída de los puntos cardinales. Seix Barral

Gamboa, S. (2005). El sindrome de Ulises.Seix Barral

García Márquez, G. (1967). Cien años de soledad. Planeta

García Márquez, G. (1981). Crónica de una muerte anunciada. Ed. Oveja Negra

Garib, W. (1971). El viajero de la alfombra mágica. Editorial Sin Frontera

Guimaraes Rosa, J. (1956). Gran Sertón. Veredas. Ed. Adriana Hidalgo

Hatoum, M. (1993). Récit d'un certain orient. Seuil

Hatoum, M. (2003). Deux frères. Seuil

Littin, M. (1999). El bandido de los ojos transparentes. Seix Barral

Maalouf, A. (2004). Orígenes. Alianza Editorial

Martínez Montalvez, P. (1985). Introducción a la literatura árabe moderna. Ed. Cantarabia

Matías, R. (1989). Escritores chilenos de origen árabe. Ed. Universitaria

Menéndez Paredes, R. (2011). Árabes de cuentos y novelas. Huerga y Fierro Editores

Parr, A. (2005). Construction de l'identité árabe-américaine. Entre invisibilité et mise en scène stratégique. L'Harmattan

Palma, R. [1877] (2017). Tradiciones Peruanas.

Saer, J. J. (1987). La Ocasión. Seix Barral

Said, E. (1990). Orientalismos. Libertarias

Said, E. (2001). Fuera de lugar. Grijalbo

Sarah, R. (1970). Los Turcos. Ed Orbe

Sayyad, A. (1999). La doublé absence. Des illunsions de l'émigré aux souffrances de l'immigré. Seuil

Sismondini, A. (2005). Les ecrivains brésiliens d’origine árabe. Revista Qantara, 56.

Ungar, A. (2006). Las orejas del lobo. Ediciones B.

Yasser, J. (1997). El movimiento literario americano-árabe en América Latina. En L. A. Corbinos (ed.), El Mundo Árabe y América Latina. Ed. Libertarias Prodhufi y UNESCO

\section{Autora}

Leyla Bartet. Escritora, periodista y Socióloga. Colabora con la revista Quehacer del Centro de Estudios y Promoción del Desarrollo (DESCO, Perú) y con un diario peruano. Conferencista invitada en las universidades francesas de Caen, Amiens, Paris y Poitiers. 